\title{
Characterisation of bending cracks in R/FRC using image analysis
}

\author{
Carlos G. Berrocal ${ }^{\mathrm{a}, \mathrm{b}, *}$, Ingemar Löfgren ${ }^{\mathrm{a}, \mathrm{b}}$, Karin Lundgren ${ }^{\mathrm{a}}$, Niclas Görander ${ }^{\mathrm{a}}$, Christopher Halldén ${ }^{\mathrm{a}}$ \\ ${ }^{a}$ Chalmers University of Technology, SE-41296, Göteborg, Sweden \\ ${ }^{b}$ Thomas Concrete Group AB, Södra Vägen 28, 41254 Göteborg, Sweden
}

\begin{abstract}
In this study, experiments were conducted to induce bending cracks of specific surface crack width to reinforced concrete beams made of plain concrete (RC) and reinforced concrete beams made of fibre reinforced concrete (R/FRC). After injecting and impregnating the cracks with dyed epoxy resin, image processing and analysis were employed to investigate the internal crack morphology. Several crack features including crack width (accumulated, effective and maximum), branching and tortuosity were defined and quantified. The results showed that in addition to arrested crack development, the presence of fibres yielded a distinctive change in the internal crack pattern, including increased branching and tortuosity, both of which have positive implications regarding concrete permeation. Likewise, specimens with fibres exhibited reduced maximum individual crack widths near the rebar, potentially increasing the ability of autogenous crack healing and reducing the risk of corrosion initiation.
\end{abstract}

Keywords: B. Crack Detection, B. Image analysis, C. Durability, E. Fibre Reinforcement

\section{Introduction}

Cracks are inherently present in virtually all reinforced concrete structures and particularly macro-cracks, i.e. those featuring a width equal to or larger than $0.1 \mathrm{~mm}$, can significantly alter the transport properties of the concrete. As reported in a number of studies investigating permeation of cement-based materials subjected to cracking [1, 2], the flow rate through a crack is strongly dependent on the crack width. As a result, macro-cracks become preferential paths through which detrimental agents can reach the reinforcement, thus increasing the probability of earlier corrosion initiation 3 .

Although a correlation does not seem to exist between the crack width in concrete and the corrosion rate of embedded reinforcement in the long term [4, 5, 6], a relation has been observed between crack width and corrosion rate at early stages [7]. Most of the available research investigating the relation between crack width and corrosion is, however, based on cracks measured at the surface, which are greatly dependent on the cover depth. On the other hand, it has been hypothesised by some authors [8, 9, 10, 11, 12, that the crack width at the reinforcement level together with the associated neighbouring areas of the steel-concrete interface affected by bond stresses, i.e. the debonded length along which the slip and separation occur, might govern the extension of the anodes formed on the rebar and might consequently be a better indicator of the risk of reinforcement corrosion.

\footnotetext{
*Corresponding author. Tel: +46 317722262

Email address: carlos.gil@chalmers.se (Carlos G. Berrocal)
}

The mechanical properties of fibre reinforced concrete (FRC) have been extensively investigated in the past, see e.g. [13, 14, 15], and today it is widely known that adding fibres to conventionally reinforced concrete members, even at low dosages, can effectively reduce their crack width and crack spacing. This finding is, however, based on the observation of the crack pattern and the measurement of cracks at the external surfaces of concrete members, see e.g. Jansson et al. [16]. Although there are a few studies in the literature where the internal cracking of reinforced concrete members has been investigated, see e.g. [17, 18, 19, 20, the information available regarding how fibres may influence the variation of the crack width along the concrete cover, i.e. the crack profile, is still very limited.

Otsuka et al. 21] studied the influence of fibre reinforcement at $1.5 \%$ vol. on the internal cracking of dog bone specimens made of high performance cementitious composites and reinforced by a single $\varnothing 16 \mathrm{~mm}$ ribbed bar. Using a novel setup consisting of X-ray imaging of the specimens loaded under uniaxial tension while injecting a contrast medium, they were able to monitor the evolution of the internal cracking process. They observed that in the fibre reinforced composites a large number of internal micro-cracks growing from the lugs were generated along the rebar. However, no detailed measurement of the crack width was performed and only qualitative information of the crack pattern was provided. In another study, Lárusson [22] used an engineered cementitious composite (ECC) containing 2\% vol. of polyvinyl alcohol (PVA) fibres to cast prisms with partially exposed reinforcement. Using high definition digital image correlation techniques, 
the formation and propagation of the internal cracking and interfacial damage caused by uniaxial tension loading were monitored and quantified on a micro-scale. Results showed that ECC specimens featured multiple narrow cracks as opposed to RC specimens in which a wide localized crack tended to form. Similarly the slip and separation measured at the interface indicated that ECC members presented a reduced bond degradation compared to their RC counterparts.

Although fibre reinforced cementitious materials can exhibit pseudo-strain harderning and multiple cracking, this requires the use of high fibre dosages ( $>1 \%$ vol.) together with relatively high performance concretes. From an economical point of view, it is interesting to explore the possibilities of combining conventional reinforcement with FRC characterized by a strain-softening response, which can be obtained by adding low fibre volume fractions to elements made of normal strength concrete.

Image analysis has been shown to be a powerful tool with a wide range of applications, including the analysis of cracks in cementitious materials, see e.g. [23, 24]. This technique was used in this study to investigate the effect of adding fibre reinforcement at low dosages $(<1 \%$ vol.) on the internal crack morphology of RC elements subjected to bending loads. The approach selected for the specimen preparation combined two different techniques previously reported in the literature, the injection of cracks under loaded conditions [19, 25] and the surface impregnation of cut samples [26, 23]. Subsequently, image processing and the analysis of digital images obtained with an optical microscope was carried out. The results here presented include a comparison of the internal crack pattern, as well as quantitative measurements of the crack width variation along the cover depth and crack tortuosity, for plain and fibre reinforced concrete beams. This study was only focused on mechanically induced cracks. The debonded length along the reinforcement, could not be assessed in this investigation due to destructive nature of the sample preparation process. Furthermore, cracks below 0.05 mm were not well captured during the image operations of thresholding and segmentation, thus the analysis of microcracks lay outside of the scope of this paper.

\section{Description of experiments}

The main objective of this study was to investigate whether low dosages of fibre reinforcement could influence the crack profile (variation of crack width along the cover depth, changes in the crack pattern or crack tortuosity) of RC elements subjected to bending loads. To that end, an experimental programme consisting of a total of 12 beam specimens was designed. In the following sections the most relevant details of the experiments are summarised and further information can be found in [27].

Based on the type of fibre reinforcement used, the specimens were divided into three groups: a) plain concrete $(P C)$ specimens without any fibre reinforcement, which
Table 1: Experimental programme

Concrete mix designation

\begin{tabular}{cccc} 
Target & & & \\
\cline { 2 - 4 } crack width & PC & SFRC & HyFRC \\
\hline \multirow{2}{*}{$0.5 \mathrm{~mm}$} & PL-B1-0.5 & ST-B1-0.5 & HY-B1-0.5 \\
& PL-B2-0.5 & ST-B2-0.5 & HY-B2-0.5 \\
\hline \multirow{2}{*}{$1.0 \mathrm{~mm}$} & PL-B3-1.0 & ST-B3-1.0 & HY-B3-1.0 \\
& PL-B4-1.0 & ST-B4-1.0 & HY-B4-1.0 \\
\hline
\end{tabular}

acted as control specimens; b) steel fibre concrete $(S F R C)$ specimens including $35 \mathrm{~mm}$ end-hooked steel fibres; and c) hybrid fibre reinforced concrete $(H y F R C)$ specimens featuring a blend of steel fibres and $8 \mathrm{~mm}$ straight micro-PVA fibres.

The beams in each group were further divided into two sub-groups according to the crack width opening aimed at during the bending tests, either 0.5 or $1.0 \mathrm{~mm}$, to investigate the influence of the maximum surface crack width. Note that in the following, the term Crack Mouth Opening Displacement (CMOD) will be used to refer to the crack width measured with a clip gauge during the bending tests whereas Crack Tip Width (CTW) will be used to refer to the crack width at the notch tip assessed by optical microscopy.

Two beams were tested for each concrete mix and crack width (e.g. B1 \& B2) as presented in Tab.1. Note that out of each beam, two longitudinal sections were cut (denoted A \& B). Therefore, a total of 24 crack specimens were processed and used for image analysis. When referring to individual crack specimens, the notation presented in Tab. 1] is extended by adding the letter A or B at the end, e.g. PL-B1-0.5 A.

\subsection{Specimen geometry}

In this study, the geometry of the specimens used to characterise the flexural behaviour of reinforced concrete mixes according to EN 14651:2007 28] was adopted, i.e. beams featuring $150 \times 150 \times 550 \mathrm{~mm}$ dimensions. However, two modifications were introduced in the setup: (i) the depth of the notch sawn at the centre of the tensile face aimed at creating a stress raiser to ensure the initiation of the main crack at that location was reduced to only $10 \mathrm{~mm}$; (ii) two ribbed $\varnothing 10 \mathrm{~mm}$ reinforcement bars with bent ends were embedded with a clear cover from the notch tip of $50 \mathrm{~mm}$ and an inner separation between bars of $70 \mathrm{~mm}$. It must also be noted that unlike in the procedure specified in EN 14651:2007, the beams were not rotated $90^{\circ}$ with respect to the casting position during the bending tests. The geometry of the specimens is shown in Fig. 1.

\subsection{Materials and mix composition}

A self-compacting concrete mix with a water-to-cement ratio $(w / c)$ of 0.47 was used to cast all the specimens. In 


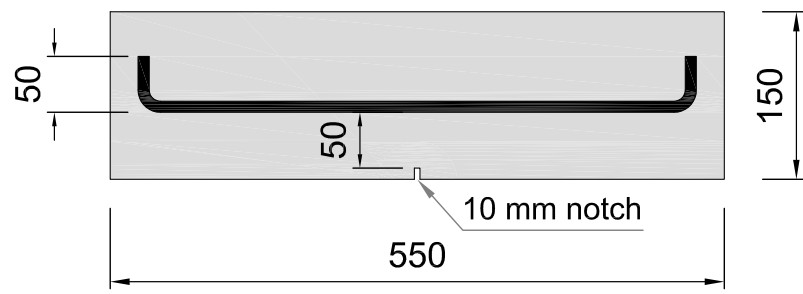

(a) Longitudinal section

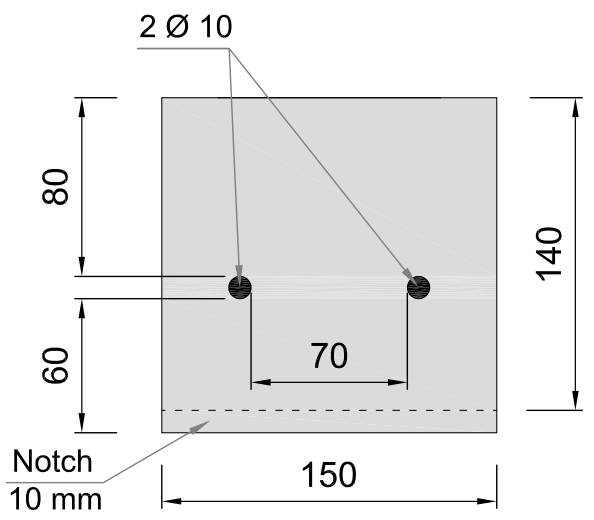

(b) Cross section

Figure 1: Geometry and reinforcement layout of beam specimens. (measurements in $\mathrm{mm}$ )

the mixes containing fibre reinforcement, the coarse and fine aggregate content was slightly reduced to compensate for the addition of the fibres. The mixture proportions are given in Tab. 2 The characteristics of the steel and PVA fibres used for the fibre reinforced mixes are summarised in Tab. 3 .

After casting, the specimens were water cured for three weeks and thereafter dry cured in a laboratory environment $\left(20 \pm 2{ }^{\circ} \mathrm{C}\right.$ and $\left.60 \pm 20 \% \mathrm{RH}\right)$ during the week preceding the bending tests.

Material tests were carried out to assess the mechanical properties of the different concrete mixes. Testing of compressive and splitting tensile strength was conducted in accordance with EN 12390-3:2003 [29] and EN 123906:2001 [30, respectively. Additionally, the flexural tensile strength of the mixes containing fibre reinforcement was tested in accordance with EN 14651:2007 [28].

Results from compressive and splitting tensile strength are summarised in Tab. 4. In Fig. 2 the flexural tensile stress is plotted against the displacement at the mid-span for each individual test whereas Tab. 5 presents the average residual flexural tensile strength at varying CMOD levels. Note that values presented in Tab. 5 for SFRC were calculated excluding the specimen exhibiting the highest performance as it deviated more than $10 \%$ with respect to the average behaviour and thus, was considered an outlier. The enhanced performance was explained by a significantly higher amount of fibres bridging the crack, 219 fibres compared to 187,178 and 176 fibres, as revealed by a scrutiny of fibres performed on the split halves of the

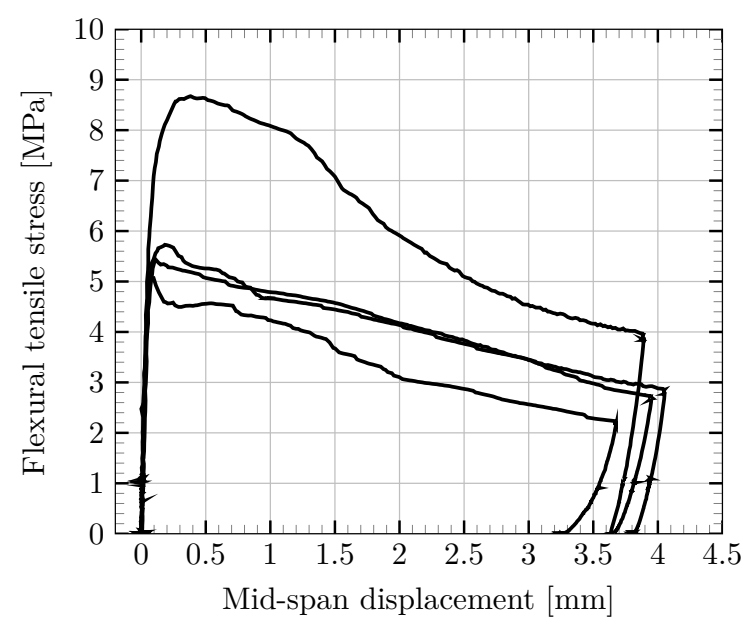

(a) SFRC

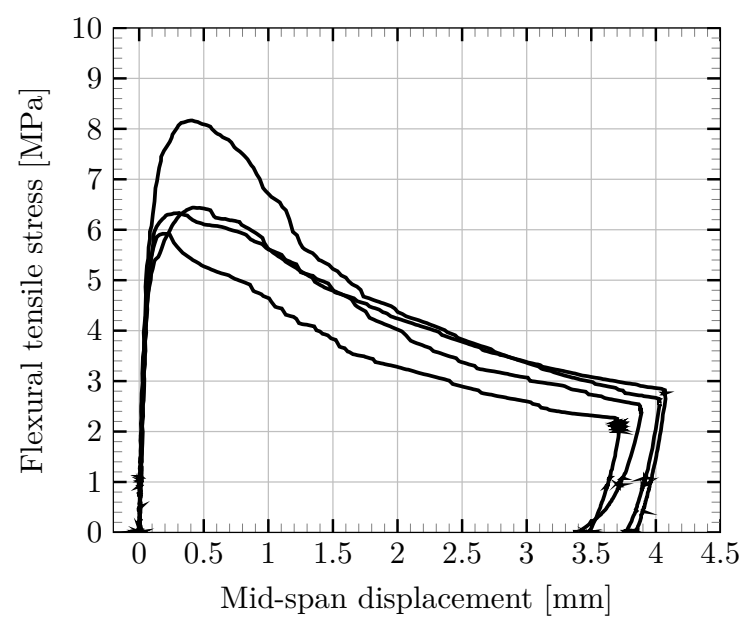

(b) HyFRC

Figure 2: Flexural tensile stress vs mid-span displacement curves for fibre reinforced concrete mixes.

tested specimens.

\subsection{Bending test setup and crack injection}

In order to induce cracking, the beam specimens were tested under a three point bending setup. In this study the beams were loaded with the notched side facing upwards, i.e. the beams were resting on a single bearing support centered underneath the bottom face while the ends were pressed downwards, see Fig. 3 .

The loading rate was kept at a displacement rate between 1.0 and $1.8 \mathrm{~mm} / \mathrm{min}$. Using a clip gauge mounted over the notch and a load cell placed under the bottom bearing support, the crack-mouth opening displacement (CMOD) and the load of the centre reaction were monitored, respectively. A comparison of the load vs. CMOD for the different beams is presented in Fig. 4 Observe that the maximum loads applied on the fibre reinforced specimens were generally 30 to $40 \%$ larger than the maximum loads applied on the plain concrete specimens in order to 
Table 2: Mixture proportions, in $\mathrm{kg} / \mathrm{m}^{3}$

\begin{tabular}{lccc}
\hline & \multicolumn{3}{c}{ Concrete mix designation } \\
\cline { 2 - 4 } Component & $P C$ & SFRC & HyFRC \\
\hline Cement (CEM I 42.5N SR 3 MH/LA) & 360 & 360 & 360 \\
Limestone filler (Limus 40) & 165 & 165 & 165 \\
Fine aggregate (sand 0/4) & 776 & 768 & 767 \\
Coarse aggregate (crushed 5/16) & 840 & 833 & 831 \\
Effective water & 169 & 169 & 169 \\
Superplasticizer - Glenium 51/18 & 5.76 & 5.76 & 5.76 \\
Air entrainer - MicroAir 105 & 0.36 & 0.36 & 0.36 \\
\hline Fibre (vol.\%) & Plain & Steel & Hybrid \\
\hline Steel - Dramix ${ }^{\circledR}$ 65/35-BN & - & 0.5 & 0.5 \\
PVA - Kuralon ${ }^{\text {TM }}$ RSC15/8 & - & - & 0.15 \\
\hline
\end{tabular}

Table 3: Fibre reinforcement properties (supplier specifications)

\begin{tabular}{lcc}
\hline Property & $\begin{array}{c}\text { Dramix } \\
\text { 65 }\end{array}$ & $\begin{array}{c}\text { Kuralon }^{\text {TM }} \\
\text { RSC15/8 }\end{array}$ \\
\hline Material & $\begin{array}{c}\text { Low carbon } \\
\text { steel }\end{array}$ & $\begin{array}{c}\text { Polyvinyl } \\
\text { Alcohol }\end{array}$ \\
Length $[\mathrm{mm}]$ & 35 & 8 \\
Diameter $[\mu \mathrm{m}]$ & 550 & 40 \\
Aspect ratio & 65 & 200 \\
Shape & End-hooked & Straight \\
Tensile Strength $[\mathrm{GPa}]$ & 1.1 & 1.4 \\
Young's Modulus $[\mathrm{GPa}]$ & 210 & 35 \\
\hline
\end{tabular}

Table 4: Compressive and splitting tensile strength results

\begin{tabular}{lcccc}
\hline & \multicolumn{2}{c}{$\begin{array}{c}\text { Compressive } \\
\text { strength }\end{array}$} & \multicolumn{2}{c}{$\begin{array}{c}\text { Tensile } \\
\text { strength }\end{array}$} \\
\cline { 2 - 5 } Mix & Average & COV (\%) & Average & COV (\%) \\
\hline PC & 58.8 & 1.8 & 3.0 & 7.1 \\
SFRC & 55.3 & 3.5 & - & - \\
HyFRC & 51.4 & 4.3 & - & - \\
\hline
\end{tabular}

Table 5: Average residual flexural tensile strength of FRC mixes, according to 28

\begin{tabular}{lcc}
\hline & \multicolumn{2}{c}{$f_{R}$} \\
\cline { 2 - 3 } $\begin{array}{c}\text { CMOD } \\
{[\mathrm{mm}]}\end{array}$ & $\begin{array}{c}\text { SFRC } \\
{[\mathrm{MPa}]}\end{array}$ & $\begin{array}{c}\text { HyFRC } \\
{[\mathrm{MPa}]}\end{array}$ \\
\hline 0.5 & 4.99 & 6.51 \\
1.0 & 4.69 & 6.02 \\
1.5 & 4.44 & 5.13 \\
2.0 & 4.14 & 4.48 \\
2.5 & 3.79 & 3.99 \\
\hline
\end{tabular}

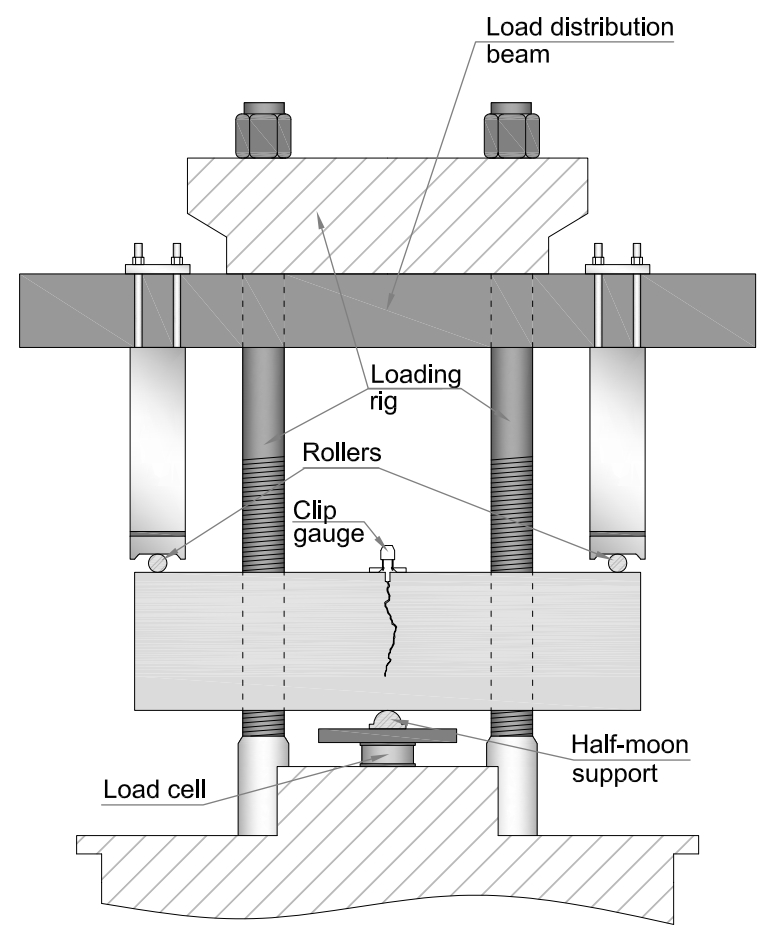

(a)

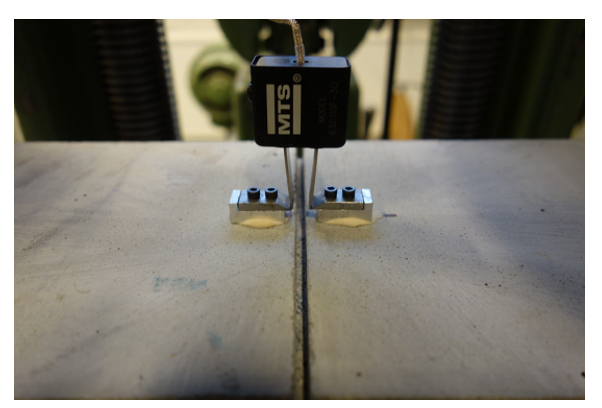

(b)

Figure 3: Bending test setup: (a) general view; (b) detail of the clip gauge over the notch. 


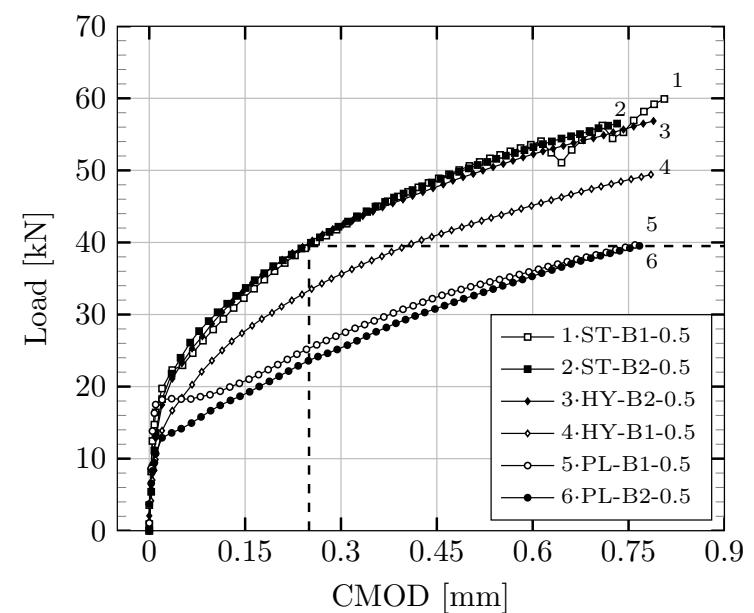

(a)

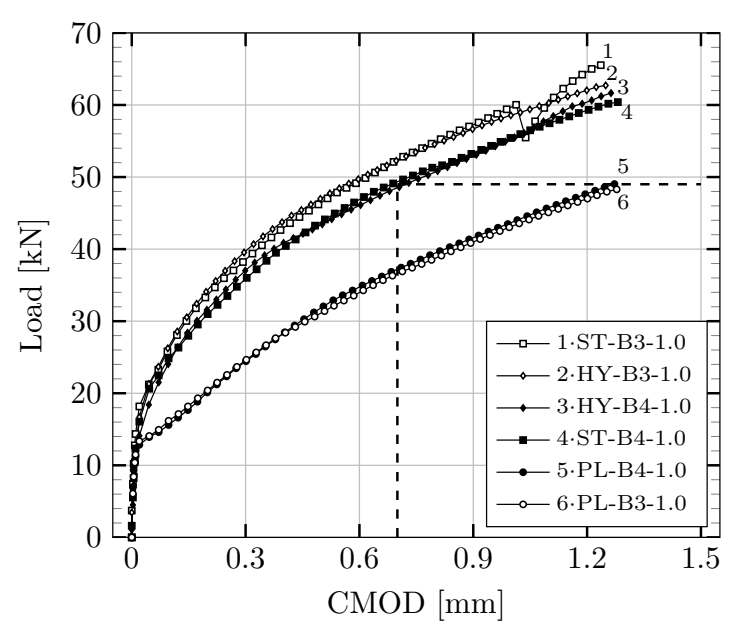

(b)

Figure 4: Load vs CMOD curves for the cracking process of the beam specimens. Note the differing scales on the x-axes. Dashed lines indicate the CMOD of FRC mixes at the maximum load reached for PC specimens.

reach the same CMOD. From Fig. 4 it can also be observed that if the bending tests had aimed at reaching a certain load, the cracks formed in the fibre containing specimens would have been significantly smaller (60\% or less). Consequently, the experiments were aimed at achieving a specific crack width rather than a certain load level in order to ease the evaluation and comparison of the crack width profile between the different mixes. It must be noted that the major influence of fibres on the load vs. CMOD curve may be partly attributable to the particular geometry of the specimen used in this study in which the concrete cover comprised one third of the total depth of the beam.

During the loading procedure, the crack width opening at the tip of the notch (CTW) was determined using an optical crack-detection microscope. Once the target crack width had been reached, the loading rig was fixed ensuring a constant deformation to maintain the crack open. A low viscosity epoxy resin $(0.10 \mathrm{~Pa} \cdot \mathrm{s})$ mixed with fluorescent dye was used to inject the crack with the aid of a syringe. The notch, acting as a small reservoir, was continuously filled allowing the resin to slowly penetrate inwards until the crack did not admit any further resin. Hot-melt adhesive had been previously applied on the lateral faces of the beam to seal the crack and prevent the resin from leaking. After injecting the crack, the resin was left to harden for a minimum period of 16 hours before removing the load, to limit the recovery of crack closing.

\subsection{Sample preparation and vacuum impregnation}

Given the influence of cracks on the ingress of external agents into concrete that may cause the degradation of reinforcement, the sections of the beam where the induced cracks intersected the reinforcement bars became of special interest. Consequently, after the resin had completely hardened, the central part of the beams was cut using a water-cooled diamond saw and out of it two smaller specimens were sawn by performing two cuts parallel to the reinforcement, as shown in Fig. 5(a) An additional vacuum impregnation with fluorescent epoxy resin was performed on the resulting two specimens obtained from each beam to ensure that secondary narrower cracks were also filled with resin. Subsequently the specimens were ground to remove the excess of resin and provide a polished surface adequate for microscopy and analysis. Fig. 5(b) shows the final result of the cutting and vacuum impregnation process.

\section{Image analysis}

In this investigation image analysis was employed to provide a quantitative characterisation of the cracks induced in the beam specimens under bending. In the following sections, the various aspects of the procedure followed to complete the processing and analysis of the digital images are described. It must be noted, however, that it was not the intention of this study to develop a tool for automated crack detection nor for image segmentation.

\subsection{Image acquisition}

Image acquisition was performed on all specimens by using a SteREO Discovery.V20 microscope outfitted with a CCD AxioCam MRc5 digital camera under computer controlled light conditions. The images produced by the camera had a maximum resolution of 5 megapixels and 16 bit RGB color depth. Each individual image mapped a region of $7.0 \times 5.24 \mathrm{~mm}$, providing a resolution of $2583 \times 1936$ pixels $(2.7 \mu \mathrm{m} /$ pixel $)$ which was considered sufficient for this investigation.

Images were taken along the path of the main crack and also along secondary cracks branching out from or running parallel to the main crack. The auto-alignment feature available in the AxioVision software, automatically detects the overlapping region between adjacent images thus determining the correct position of each individual 

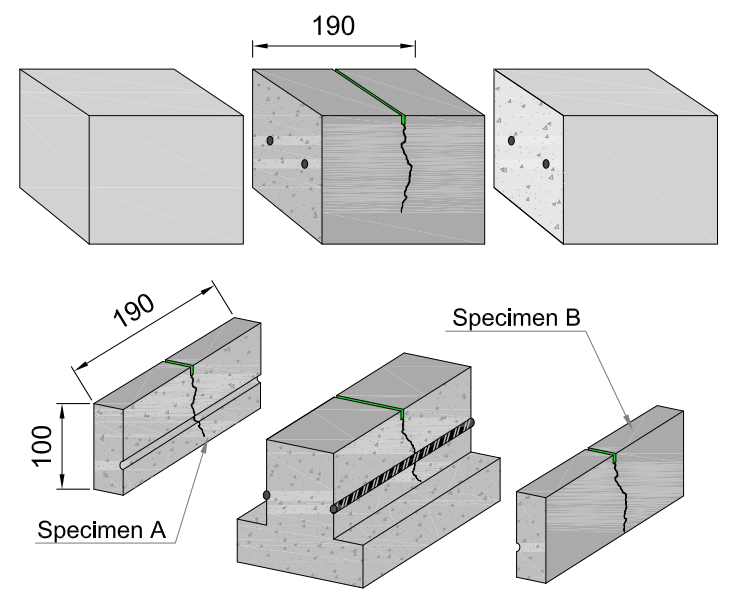

(a) Cutting scheme of beams with injected cracks

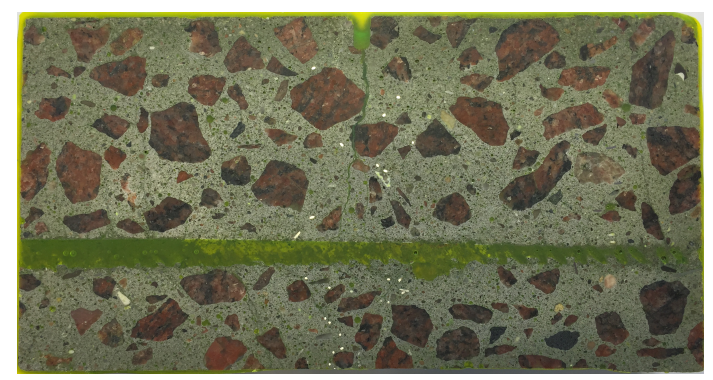

(b) Specimen after vacuum impregnation and surface grinding

Figure 5: Process of sample preparation. (measurements in $\mathrm{mm}$ )

image in the general picture and obviating the duplicated overlapping region. Taking advantage of this feature, each crack was reconstructed by merging between 20 and 30 images taken at a 20x magnification. In Fig. 6(a) the full length of a crack obtained by image reconstruction is shown.

\subsection{Image processing}

The colour images obtained from the image acquisition procedure were processed to attain binary images displaying the actual crack pattern without the background noise to facilitate the subsequent analysis and measurement of the crack features. The processing of the images involved three main tasks, thresholding, cleaning and filtering, each of which entailed one or more operations. In order to perform these operations, which are described in the following sections, the freely available software image J [31] was employed.

Thresholding can be performed by selecting a combination of ranges for the intensity of each of the three colour channels in the RGB colour space. However, although the areas impregnated by the dyed resin could be easily distinguished from the background matrix by the naked eye, given the high variability of the colour hue in the resin, it was not feasible to set a fixed threshold for each image. Working in the HSB (Hue, Saturation, Brightness) colour space was found to be more appropriate since the hue range of the resin remained nearly constant throughout the various images. The thresholding operation was performed in a semi-automated way following two steps: a) initially, an automatic thresholding based on an input sample of the impregnated crack region was performed; b) after that, the three histograms of the HSB colour space were manually adjusted based on a visual observation of the boundary between the crack and the concrete matrix. Fig. 6(c) shows the result of applying the thresholding operation to the small region of the crack displayed in Fig. 6(b)

As observed, the contour and area of the crack displayed in the resulting binary image obtained from the thresholding operation were still poorly defined and needed further processing. Therefore, the binary images were subjected to a cleaning process by applying a morphological opening operation (an erosion followed by a dilation) to remove background noise (specially near the main crack), followed by a filling operation to include minor holes undetected during the thresholding operation. A 2D-median filter with a 5 pixel disk structuring element was also applied towards the end to smooth the crack edges.

Finally, a filter operation was performed to remove the numerous particles in the background corresponding to the presence of pores or micro-cracks filled with resin during the vacuum impregnation. Since cracks were generally much larger than the background noise particles and since they presented a high length-to-width ratio, a filter based on the minimum area and maximum circularity was applied to isolate the particles belonging to the crack pattern. Larger defects such as air voids were manually removed when necessary. Fig. 6(d) shows the resulting binary image after cleaning and filtering. As observed later, any minor difference between the contours of the original and processed images will be insignificant with respect to the variation of the crack width along the length of the crack.

\subsection{Determination of the crack features}

\subsubsection{Crack width}

Cracks are highly irregular and continuously change direction as they propagate through the concrete, presenting rough faces when observed under the microscope. As discussed in [19], the exact width of individual cracks becomes, in many cases, a matter of definition or judgement in reading. The uncertainty stemming from the reading of an observer disappears when using image analysis since the accuracy is limited by the resolution of the images. Thus, determining the width of a crack becomes solely a problem of definition.

Unfortunately, there is no unequivocal way to define cracks. For instance, Qi et al. 24] used image analysis to measure the crack width of plastic shrinkage cracks formed along a stress raiser on slab specimens. They adopted an approach in which the crack width was determined to be the length of the segments resulting from subtracting a 


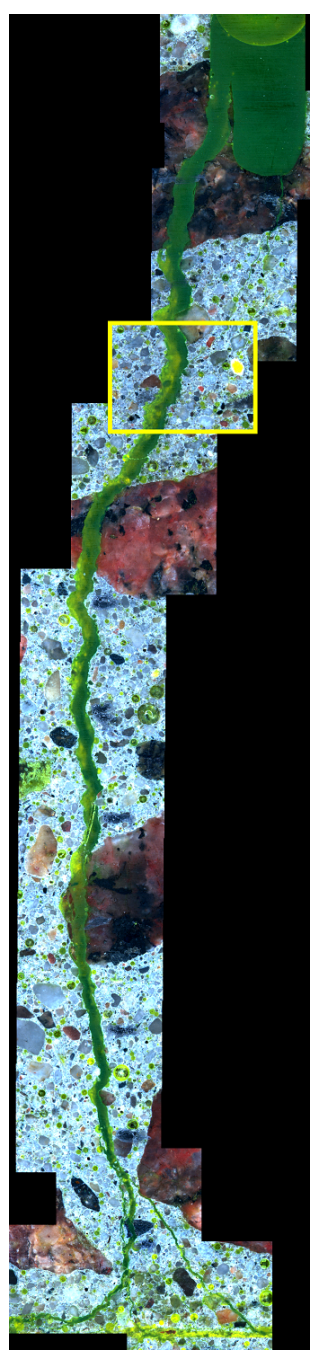

(a) Original image

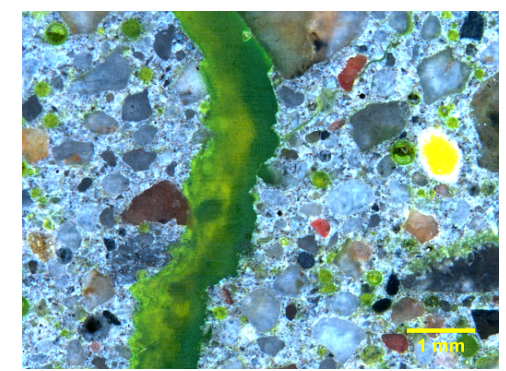

(b) Zoomed-in region highlighted in (a)

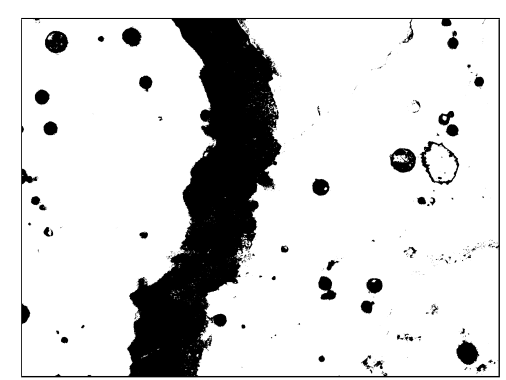

(c) Binary image after thresholding

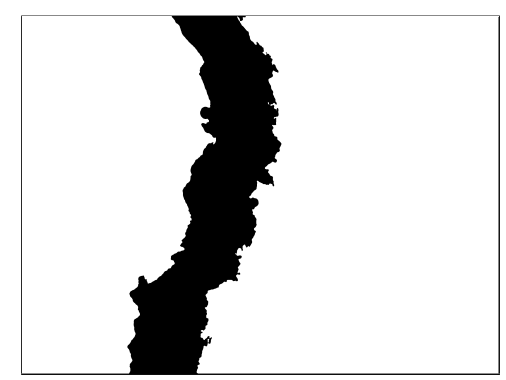

(d) Image after cleaning and filtering
Figure 6: Example of image pre-processing from acquired images.

certain grid mask, consisting of equally spaced lines in the perpendicular direction of the stress raiser, from the binary image of the cracks. In other words, they determined the crack width as the width of the cracks perpendicular to a pre-established global direction of propagation. This method is very straight forward and is especially attractive considering the matrix nature of the pixel arrangement within an image.

However, as stated by Qi et al. 24, when the direction of the crack changes, due to such factors as the presence of aggregates or fibres, and becomes nearly horizontal, the crack width, locally, would be greatly overestimated. In fact, as soon as the direction of the crack deviates from the global direction of propagation, the crack width measured perpendicularly to the global or local directions of propagation differs, a difference that rapidly increases as the angle of deviation increases. Consequently, for cases in which the crack pattern presents high tortuosity, this approach could introduce a significant error. Furthermore, in the study of the influence of cracks on the transport properties of concrete, it seems more reasonable to adopt a crack width perpendicular to the local direction of propagation. It should be noted nonetheless that the cracks presented in this study are the intersection of the "real" crack, i.e. a three-dimensional fracture surface, with the cut plane and, as a result, measured crack widths might still be overestimated due to the out-of-plane inclination of the crack.

An additional problem arises when multiple cracks coexist, e.g. due to branching. In order to compare cracks from different specimens, a certain equivalent crack width needs to be defined when more than one crack is present, which can be defined differently depending on the properties that are of interest. In this study, three different definitions were used: (1) the total or accumulated crack width, $w_{t}$, as a measure of the total crack variation between the surface and the reinforcement; (2) the effective crack width, $w_{e f}$, in this case defined as the crack width yielding a flow equivalent to the accumulated flow from each individual crack based on Poiseuille's law [32], which is relevant for permeation; and (3) the maximum individual crack width, $w_{\max }$. These crack widths can be mathematically defined as follows:

$$
\begin{gathered}
w_{t}=\sum_{i=1}^{n_{c}} w_{i} \\
w_{e f}=\sqrt[3]{\sum_{i=1}^{n_{c}} w_{i}^{3}} \\
w_{\max }=\max \left\{w_{1}, \ldots, w_{i}, \ldots, w_{n_{c}}\right\}
\end{gathered}
$$

where $w_{i}$ represents the individual crack widths, $n_{c}$ the total number of cracks at a certain distance from the concrete surface and $w_{t}, w_{e f}$ and $w_{\max }$ are the total, effective and maximum crack widths, respectively.

\subsubsection{Crack branching}

Crack branching can be defined as the bifurcation of one crack into two or more cracks, generally smaller than the original crack. Consequently, this phenomenon can be directly related to the effective crack width defined in Sec. 3.3.1 and thereby to the permeation of cracked concrete. It is therefore interesting to define a parameter to quantify the influence of fibre reinforcement on crack branching. In this study, a parameter, $\beta$, has been defined as the ratio between the cumulative crack length projected onto the vertical direction and the cover depth, which can be expressed as in Eq. 4 (see Fig. 7(a) for illustration).

$$
\beta=\frac{\sum_{i=1}^{n_{c}} L_{p r, i}}{\text { cover }} \geq 1
$$

where $L_{p r, i}$ represents the individual crack lengths projected onto the vertical direction and cover is the thickness of the concrete cover which is $50 \mathrm{~mm}$ for purposes of this study. 


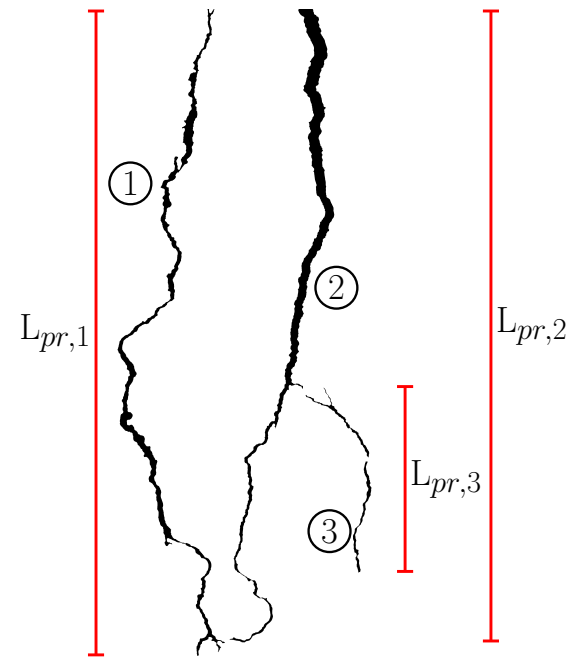

(a)

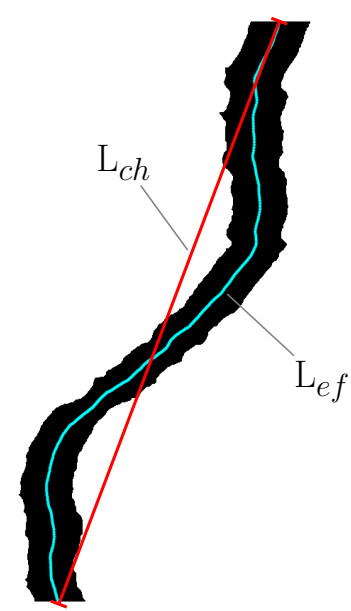

(b)

Figure 7: Digitalised crack segments used to illustrate (a) the concept of branching and (b) the concept of tortuosity.

\subsubsection{Crack tortuosity}

Cracks constantly change direction as they propagate through the concrete cover, resulting in complex and sinuous crack paths. The relation between the actual or effective length of a crack and the distance between its ends is called tortuosity, which is sometimes referred to as macroscopic roughness. It has been stated that permeation is proportionally decreased with the square of the tortuosity 33 as it influences both the pressure gradient and the fluid velocity and consequently it is sometimes defined as the square of the ratio mentioned. However, in this study the tortuosity of a single crack is defined as follows:

$$
\tau_{i}=\frac{L_{e f, i}}{L_{c h, i}} \geq 1
$$

where $L_{e f, i}$ and $L_{c h, i}$ are the effective length and chord length of the crack, respectively, as illustrated in Fig. $7(\mathrm{~b})$ When crack branching occurs, an averaged tortuosity, $\bar{\tau}$, is calculated for the purpose of comparison. A weighted average in which the weight coefficients represent the individual effective lengths of each crack is used to account for the size effect, i.e., shorter cracks will not be affected to the same extent by large aggregates as long cracks. Mathematically, the averaged tortuosity can be expressed as:

$$
\bar{\tau}=\frac{\sum_{i=1}^{n_{c}} \tau_{i} \cdot L_{e f, i}}{\sum_{i=1}^{n_{c}} L_{e f, i}} \geq 1
$$

It should be mentioned that tortuosity has been defined by others, see 33 , as the ratio between the effective and the projected lengths, which generally yields results similar to Eq. 5 However, this definition of tortuosity is dependent on the orientation of the crack and tends to infinity as the crack approaches a horizontal direction of propagation. Consequently, when individual cracks propagating nearly horizontally are present, this definition is no longer suitable to describe the crack tortuosity.

\subsection{Measurement of the crack width}

As mentioned in Sec. 3.3.1 in the cases in which the cracks are prone to change direction or to branch out, measuring the crack width perpendicularly to the direction of crack propagation would be preferable. This outcome could be achieved, by for instance differentiating the curve represented by the centreline of the crack and computing the perpendicular direction at every point where a measurement is desired. In this investigation, however, a different approach was adopted. Using the bwdist function implemented in the Image Processing Toolbox of Matlab ${ }^{\circledR}$ [34, the background distance, i.e. the euclidean distance of each pixel to their closest background pixel, was computed. The result of performing this operation to a small region of the image shown in Fig. 6(d) is graphically presented in Fig. 8, where black pixels constitute the background and each pixel in the crack is assigned a gray scale value, the brightness of which is proportional to the distance to the closest black pixel.

As observed in Fig. 8, there is a set of pixels aligned with the centreline of the crack that locally exhibits maximum brightness, i.e. maximum distance to the background. The pixels found along that line are located at the same distance to both subspaces in which the crack divides the background. Consequently, the background distance of the pixels located at the centreline can be regarded as the semi-width of the crack. By finding points along the centreline and computing twice the background distance, the variation of the crack width along the cover depth can be effectively determined. An algorithm based on the concept of arc-length was implemented to track those points, which is described in Appendix A 


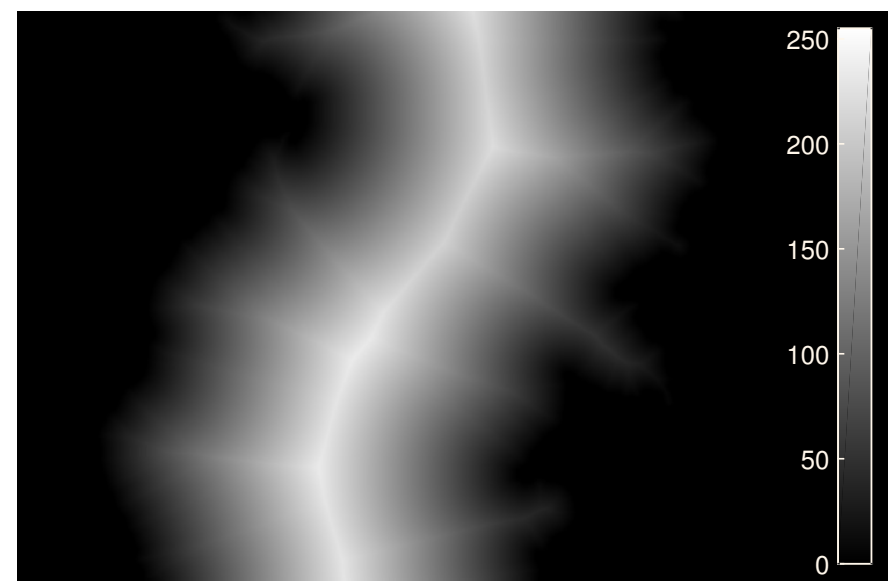

Figure 8: Example of bwdist operation performed in a small region of a binary image of crack with Matlab 34 used to illustrate to concept of "background distance".

\section{Results and discussion}

An example of the results obtained from applying the procedure described in Sec. 3.4 is shown in Fig. 9. As observed, crack width measurements taken at relatively small intervals, denoted by the markers, presented significant variability. This variability of the crack width along the concrete cover has been previously described by others, cf. [19, 20]. In order to facilitate the comparison of results, a smoother curve was fitted to the raw data by applying a Savitzky-Golay filter [34, with a span of 15 data points and a first order polynomial. The resulting curve is plotted in Fig. 9 as a thicker, continuous line. The accuracy of the method here presented was validated against manual measurements carried out using an optical crack microscope with a $20 \mathrm{x}$ magnification and a resolution of $0.02 \mathrm{~mm}$. Note that whenever equivalent crack widths, either total, effective or maximum, are presented, they were computed from the raw data before applying any filter.

\subsection{Crack pattern}

A distinctive change in the crack pattern was observed among the specimens made of the different mixes. A representative example of the crack pattern for each mix is presented in Fig. 10. The crack pattern of the remaining specimens can be found in Appendix B

$P C$ specimens generally exhibited a single, wide crack running approximately perpendicular to the reinforcement bar thereby featuring moderate tortuosity. Branching was only sporadic and multiple cracks occurred almost exclusively at the region near the reinforcement. These secondary cracks, however, seemed to grow from the reinforcement towards the main crack, usually not reaching it, as shown in Fig. 10(a), suggesting they were likely bondstress cracks as described by Goto [18].

In $S F R C$ specimens, containing only steel macro-fibres, branching was more frequent than for $P C$ specimens while a small increase in the tortuosity was seen. Branching was

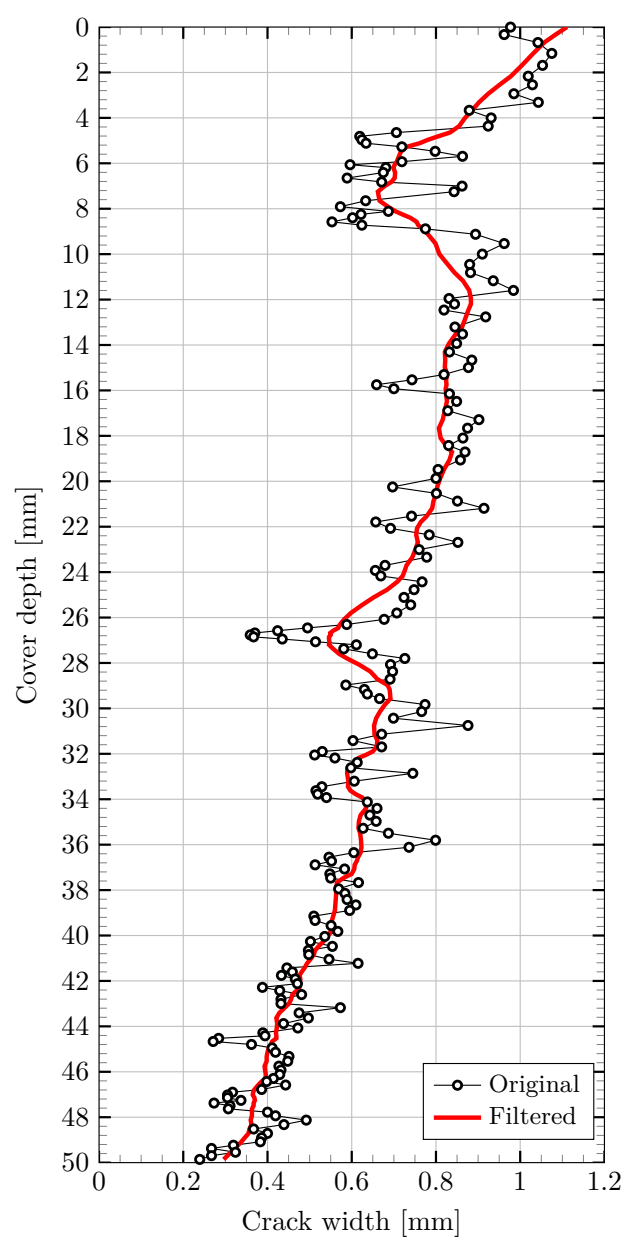

Figure 9: Crack width profile of a single crack: markers show individual measurements of the crack width along the crack path and the continuous line represents the same data after applying a SavitzkyGolay filter.

mainly observed in the lower half of the cover, close to the reinforcement, or near the notch whereas the main crack usually split only once or twice into well-defined smaller cracks as shown in Fig. 10(b)

Finally, HyFRC specimens, combining steel macroand PVA micro-fibres, often exhibited multiple branching which occurred along the whole crack length and an increase of the tortuosity became apparent. Unlike in the other two mixes, branching often resulted in complex, illdefined systems of tiny and discontinuous cracks as exemplified by the crack pattern shown in Fig. 10(c)

Branching and tortuosity were quantified based on the parameters defined by Eq. 4 and Eq. 6 and the results are presented in Fig. 11 and Fig. 12, respectively. As observed, both branching and tortuosity increased when steel fibres were present and further increased when micro-fibres were added. However, although both parameters followed the same trend, no clear relation could be observed between them based on a comparison of individual specimens.

Furthermore, in the mixes containing fibre reinforcement, branching seemed to increase as the crack open- 


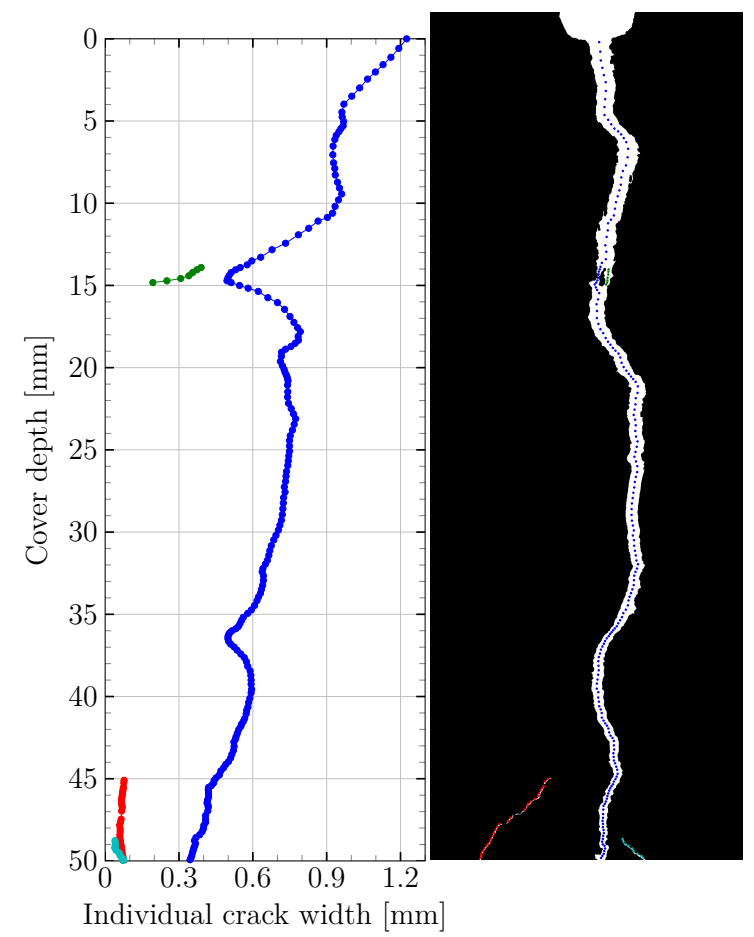

(a) Specimen PL-B4-1.0 A

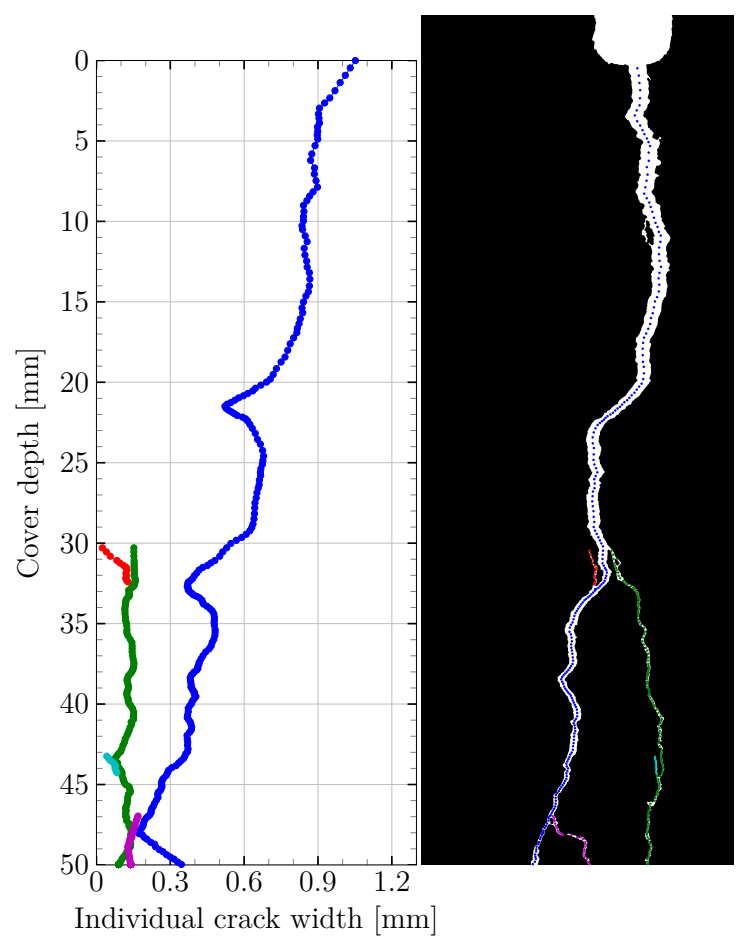

(b) Specimen ST-B4-1.0 A

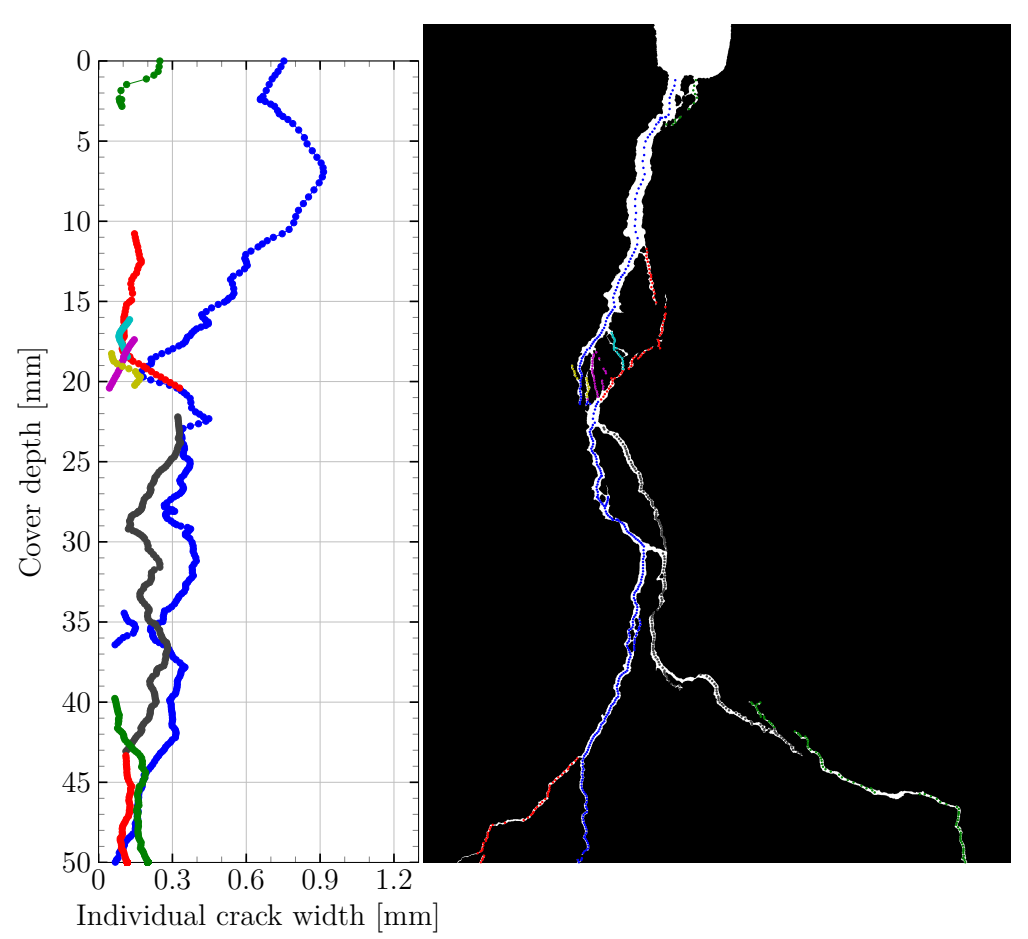

(c) Specimen HY-B4-1.0 B

Figure 10: Example of the crack pattern for different mixes and tracking of individual cracks. 


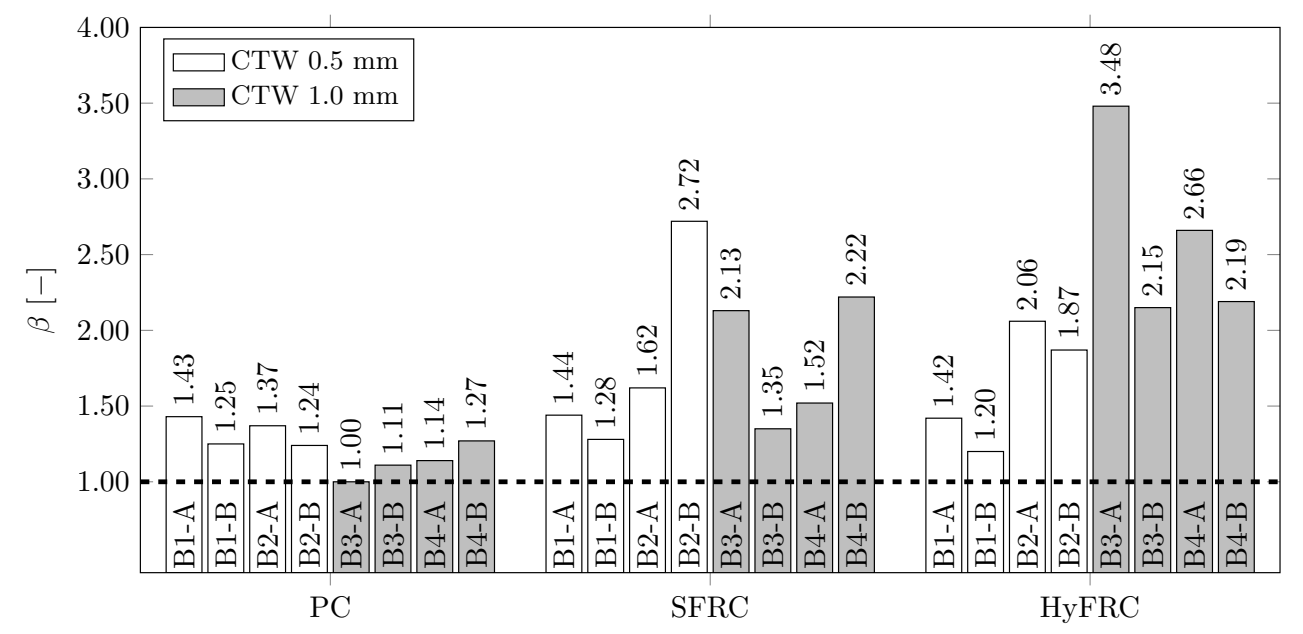

Figure 11: Branching coefficient as defined in Eq. 4 for all the cracks studied.

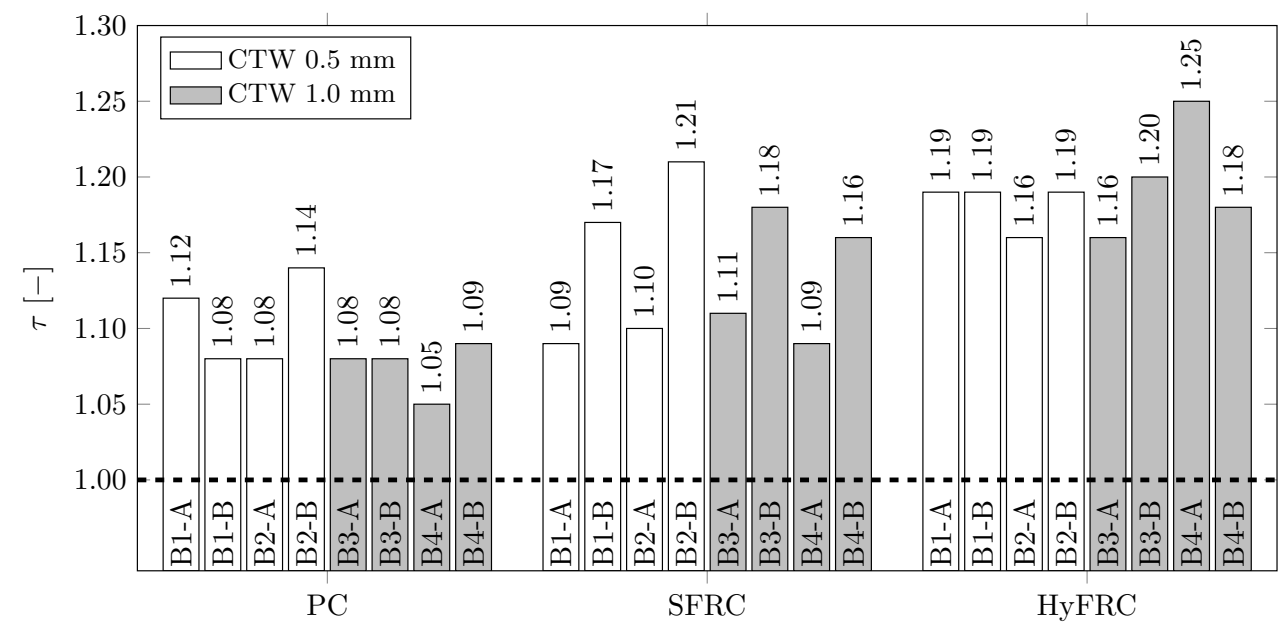

Figure 12: Average tortuosity coefficient as defined in Eq. 6 for all the cracks studied.

ing increased whereas tortuosity appeared to be independent of the crack width. This behaviour is reasonable as new secondary cracks might have appeared when the main crack opened and bridging fibres were activated transferring bond stresses to the neighbouring concrete. On the other hand, once a crack was formed, the average tortuosity did not necessarily have to increase as the main crack opened, even if new secondary cracks were formed.

The scatter found in the average tortuosity of $S F R C$ specimens is noteworthy. Given the low dosage of fibres used and the fact that cracks were only studied at certain sections of the beams, the scatter observed could be attributed to the probability of having a steel macro-fibre crossing the crack at the section examined. Furthermore, this outcome reveals a systematic difference in the tortuosity of specimens obtained from the same beam, a difference that is most likely caused by local variations in the density/orientation of the fibres.

\subsection{Maximum individual crack width}

Despite having approximately the same crack width at the notch tip, as a direct consequence of branching the mixes containing fibre reinforcement exhibited smaller individual crack widths. This result is conducive to the autogenous healing of cracks. As discussed by Edvardsen 35, cracks may heal for various reasons such as the precipitation of calcium carbonate crystals, continued hydration or blocking of the flow path by impurities or detached concrete particles. These processes can take place provided cracks are sufficiently narrow. For cracks subjected to a range of hydraulic gradients, Edvardsen proposed a crack threshold below which crack self-healing would be achieved. However, in the absence of a hydraulic gradient, these crack width limitations could probably be relaxed.

Assuming a certain permissible crack width, it might be interesting to determine what percentage of the concrete cover would be potentially healed for each concrete mix. In order to address this issue, the maximum individ- 


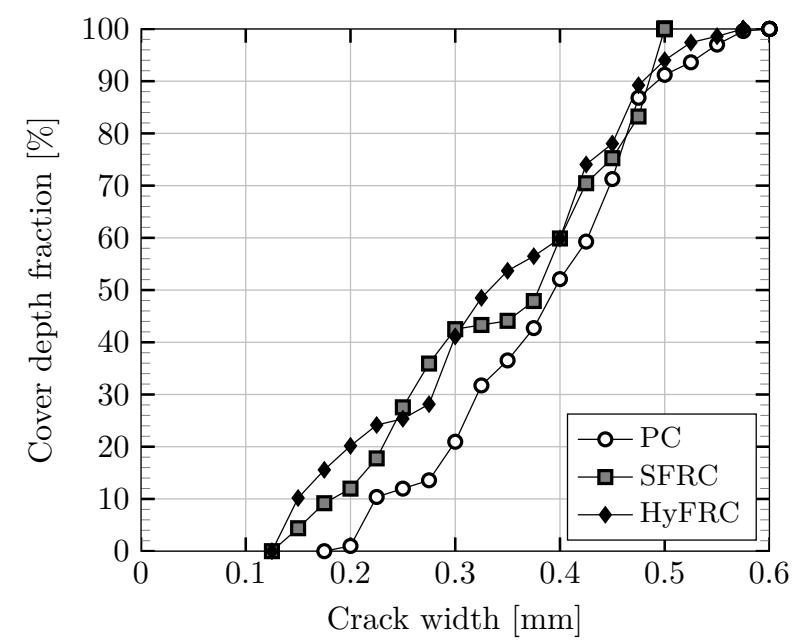

(a) $\mathrm{CTW}=0.5 \mathrm{~mm}$

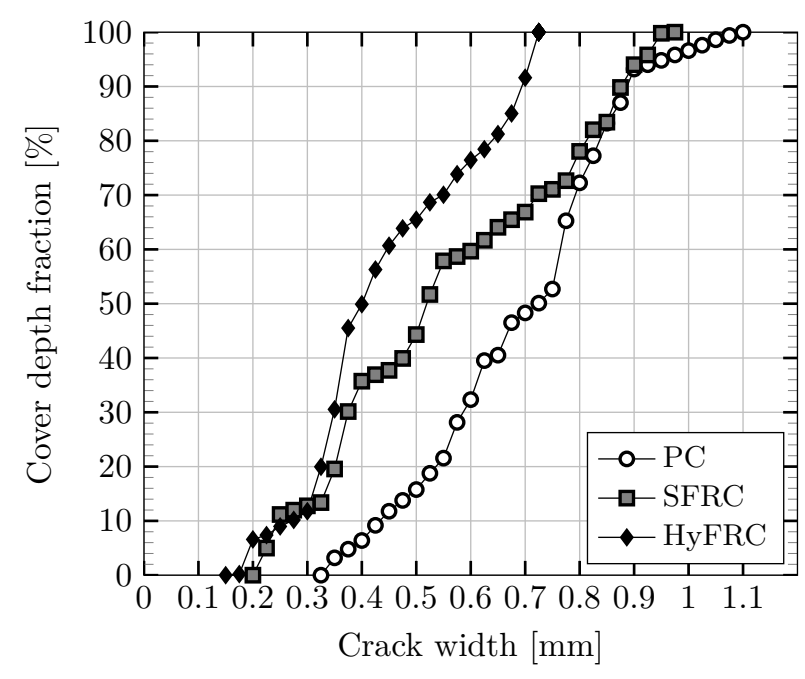

(b) $\mathrm{CTW}=1.0 \mathrm{~mm}$

Figure 13: Cumulative distribution curves showing the fraction of the cover with a crack width smaller than or equal to the $\mathrm{x}$ coordinate, presented as \% of the cover depth, for the average maximum individual crack width.

ual crack width was measured along the cover depth for each specimen and an average profile was then calculated for each mix and CTW. Subsequently, the percentage of the cover depth, in which the cracks featured a width below a certain value, was computed for several thresholds. The results are presented in the form of cumulative distribution curves in Fig. 13 It can be observed that for specimens with a CTW of $0.5 \mathrm{~mm}$ the percentage of the cover with a maximum crack width smaller than or equal to $0.2 \mathrm{~mm}$ is at least two times greater when fibres are added but the difference is reduced for increasing crack widths. A similar trend is observed for specimens with a CTW of 1.0, although the difference between plain and fibre reinforced mixes is accentuated and, in the case of HyFRC, cracks are consistently narrower throughout the entire crack width range. This observation suggests that using fibre reinforcement might contribute to a greater degree of autogenous healing in reinforced concrete members with bending cracks.

\subsection{Total crack width vs effective crack width}

The variation of total and effective crack width along the cover depth is presented in Fig 14 for the three different mixes and the two CTW investigated. The results plotted in Fig 14 are average values of the four examined cracks for each studied case. The average coefficients of variation for the PC, SFRC and HyFRC specimens were $20 \%, 18 \%$ and $31 \%$, respectively, for CTW equal to $0.5 \mathrm{~mm}$ and $11 \%$, $15 \%$ and $23 \%$, respectively, for CTW equal to $1.0 \mathrm{~mm}$. The total crack width of individual specimens, together with the calculated average total crack width, can be found in Appendix B

The first matter that should be highlighted is that the crack width profiles showed a nearly linear variation between the concrete surface and the rebar independently of the presence of fibres or the maximum crack width reached at the notch. This result might be partly explained by the large cover-to-height ratio of the beams and the fact that cracks were only analysed in the area between the notch tip and the rebar, although cracks propagated further in. Additionally, almost no difference could be observed among the different concrete mixes when comparing the accumulated crack width. However, it must be noted that fibre reinforced specimens were subjected to loads 30 to $40 \%$ higher than $P C$ specimens to achieve the same CTW. Had the load been kept at the same level, the crack widths of fibre reinforced specimens would have been a fraction of the ones obtained for $P C$ specimens, between $30 \%$ and $60 \%$ according to Fig. 4 (see dashed vertical lines).

The effective crack width, on the other hand, showed a significant difference among the mixes studied. In $P C$ specimens, as a result of limited branching, the effective crack width was generally equal to the total crack width (except in the region closest to the rebar) since both definitions coincide when only one crack is present. For $S F R C$ and $H y F R C$ a small improvement could be observed throughout the entire crack profile for the case of $0.5 \mathrm{~mm}$ CTW, and a remarkable improvement was achieved for the case of $1.0 \mathrm{~mm} \mathrm{CTW}$, especially for $H y F R C$.

The benefits of using fibre reinforcement to reduce permeation in concrete specimens exhibiting multiple through cracks as a result of the application of tensile loads have already been experimentally investigated, see e.g. [36. 37, 38. The results presented in this paper indicate that fibre reinforcement can also be beneficial in concrete elements with bending cracks, where multiple cracking is not visible at the surface but where branching occurs inside the concrete. Furthermore, an increase in the tortuosity provided by the addition of fibres, might contribute to further reducing the flow of water through the cracks thereby potentially decreasing the ingress of aggressive substances.

The implications for the corrosion of conventional reinforcement are, however, not straightforward. Whereas a 


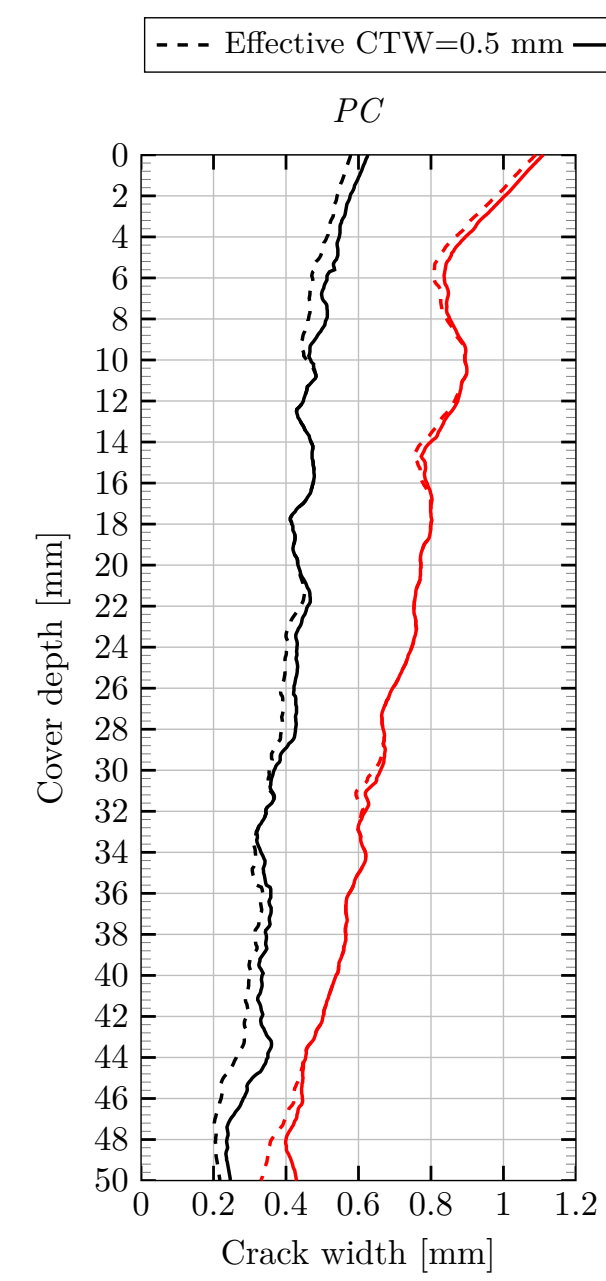

Total CTW=0.5 mm - - - Effective CTW=1.0 $\mathrm{mm} \longrightarrow$ Total CTW=1.0 mm

$S F R C$

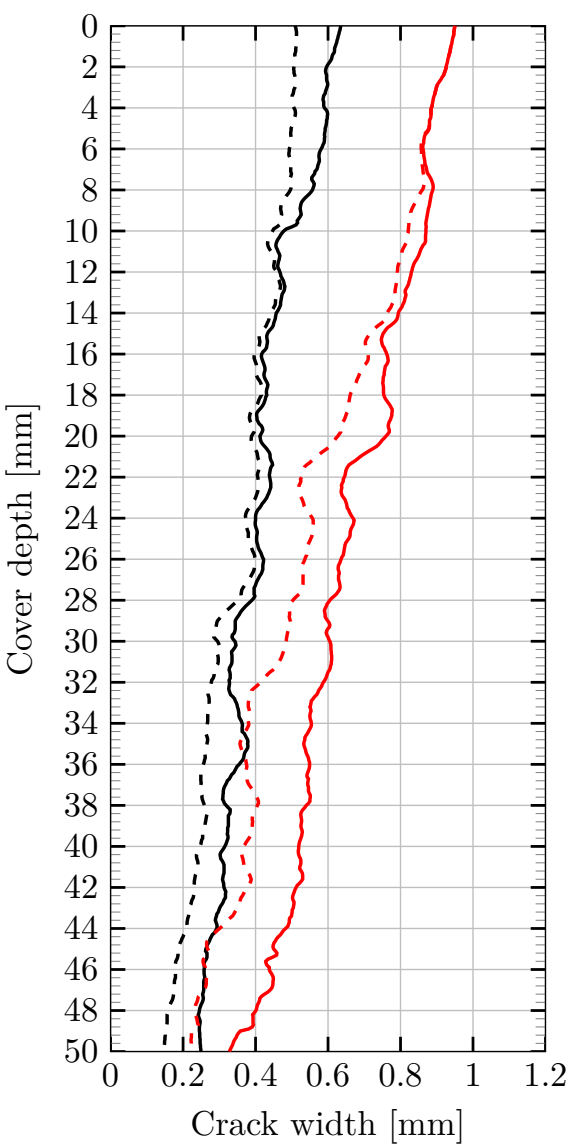

HyFRC

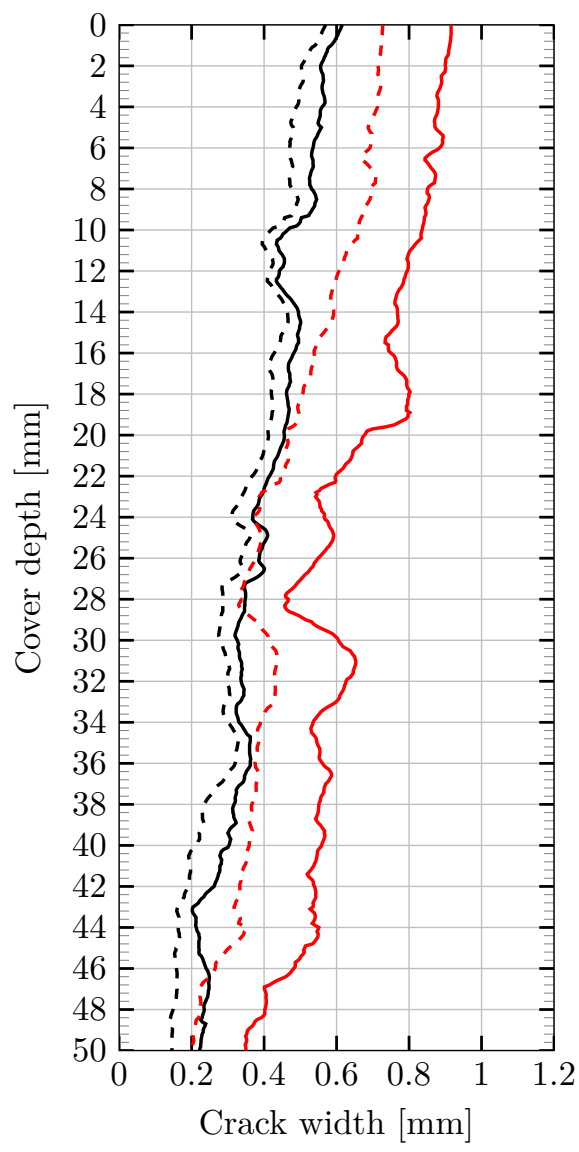

Figure 14: Comparison of the average crack width profile for all mixes.

reduced permeation and a higher tendency for crack selfhealing would likely be beneficial in terms of delayed corrosion initiation, the impact on the corrosion rate is not clear. Branching could lead to an increase in the number of areas along the rebar where corrosion might be thermodynamically favoured, whereas the reduction in individual crack widths (associated to interfacial rebar-matrix separation) could result in limited corrosion rates.

\section{Conclusions}

In this study, an experimental investigation has been carried out to characterise bending cracks in reinforced concrete beams and the influence of fibre reinforcement has been assessed.

The modified three point bending test setup based on the standard test used to characterise the flexural strength of fibre reinforced concrete mixes proved to be an effective way of studying internal cracks in reinforced concrete beams. The low viscosity $(0.1 \mathrm{~Pa} \cdot \mathrm{s})$ resin used was fluid enough to penetrate and fill the cracks and after hardening and curing, cracks were effectively prevented from closing.
Digital microscopy and image processing were found suitable for this purpose. The high resolution images taken at $20 \mathrm{x}$ maginification $(2.7 \mu \mathrm{m} /$ pixel $)$ provided an accurate description of the crack morphology at the sections studied. These images could also be used as a modelling framework for the fracture of concrete and FRC.

The algorithm implemented in this study based on the arc-length concept was capable of successfully determining the crack width perpendicular to the local direction of propagation along the whole crack path, as well as in the presence of multiple cracks. This fact permitted us to quantitatively determine several crack features even when the cracks significantly deviated from the global direction of propagation.

Results showed that despite presenting a similar crack pattern on the tensile face, i.e. a single crack, the internal crack pattern changed significantly with the addition of fibres. Whereas a single, wide crack running nearly perpendicularly to the rebar was most common for $P C$ specimens, crack branching was frequent in fibre reinforced mixes. An increase in crack tortuosity was also observed, particularly in $H y F R C$ specimens. Although the accumulated crack width remained unchanged throughout the mixes studied, 
the effective crack width was reduced by the presence of fibres. Moreover, narrower individual cracks in mixes with fibres might favour autogenous healing of cracks.

These findings, added to the significant amount of additional load needed to provide the same initial crack opening, indicate that fibre reinforcement can provide effective means of decreasing the permeability of reinforced concrete beams with bending cracks, potentially delaying the onset of corrosion at the reinforcement.

\section{Acknowledgements}

The authors want to thank The Swedish Cement and Concrete Research Institute (CBI), particularly Dr. Jan Erik Lindqvist, for providing access to their equipment and assisting with the vacuum impregnation procedure during the preparation of specimens.

\section{Appendix A. Algorithm implementation}

This appendix includes a brief description of an algorithm, based on the concept of arc-length, implemented to track points along the centreline of a crack. Using a binary image such as Fig. 8 as starting point and the concept of background distance, defined in Sec. 3.4, the arc-length approach enables to correctly track the centreline of the crack regardless of the intricacy of the crack pattern. Initially the first point of the curve was computed as the pixel possessing the absolutely maximum background distance in a horizontal row right underneath the notch tip. Subsequent points of the curve were found based on the current point as follows: a subset of points forming a $45^{\circ}$ rotated square centered at the current point at a certain diagonal length were evaluated as candidates; the pixel of the subset possessing the maximum distance was chosen as the following point of the curve. The process is schematically presented in Fig. A.1.

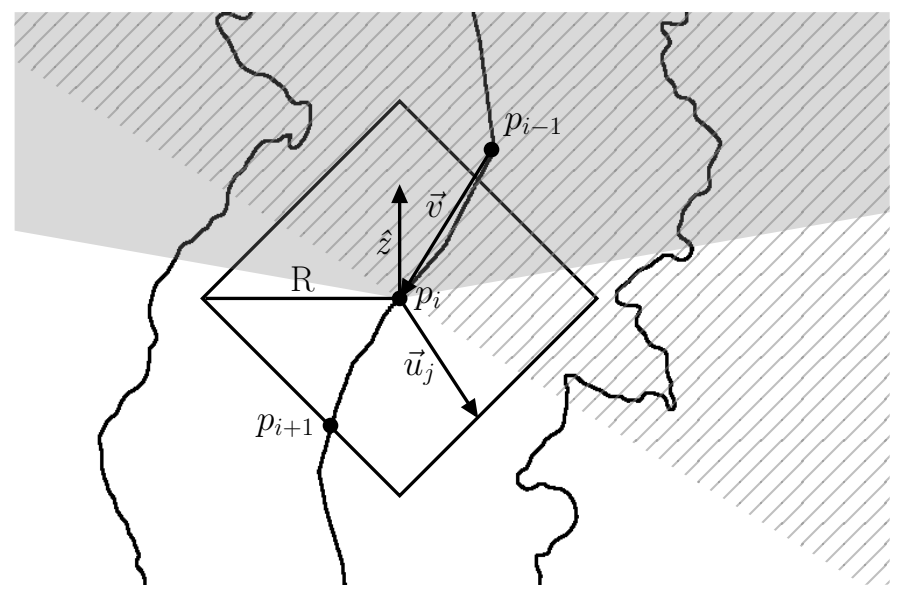

Figure A.1: Schematics of a small region of a crack illustrating the arc-length approach used to determine points along the centerline of a crack.
Two additional constraints were applied to the initial subset to ensure that the subsequent points found were located in the right direction. Based on the notation provided in Fig. A.1 the constraints can be mathematically expressed as follows:

$$
\begin{gathered}
\vec{v} \cdot \vec{u}_{j}>0 \\
\hat{\vec{z}} \cdot \frac{\vec{u}_{j}}{\left\|\vec{u}_{j}\right\|}<\cos \theta
\end{gathered}
$$

where $\vec{v}$ is the local direction of crack propagation, $\hat{\vec{z}}$ is the vertical vector of unit length assumed to coincide with the global direction of crack propagation and $\vec{u}_{j}$ represents each vector element showing the direction of the candidate points in the subset. The two constraints are graphically depicted in Fig. A.1. where the hatched and shaded areas represent the subspaces which do not fulfil the conditions expressed by Eq. A.1 and Eq. A.2, respectively.

The constraint expressed by Eq. A.1 ensures that the point found in each iteration does not return by the same path. Since $\vec{v}$ depends on the current and previous points, in the first iteration $\vec{v}$ is taken as $-\hat{\vec{z}}$. The constraint expressed by Eq. A.2 prevents the crack path from moving in the upward direction by limiting the angle the candidate points may form with the vertical direction, e.g. when two cracks merge into one. In this study it was found that $\theta=\frac{4 \pi}{9}$ yielded satisfactory results. Furthermore, the size of the square defining the initial subset of candidate points can be selected stepwise based on the local crack width to better describe the crack path. In this study, the semidiagonal of the square, R (see Fig. A.1), was chosen to be 0.5 times the local crack width.

In order to evaluate the accumulated and effective crack width of each specimen, the individual crack widths were required at the same depth. Therefore, secondary cracks were measured at the same depth as the points found along the main crack path. Their width was computed by identifying the local maxima of the background distance for the pixels in the same row as the point found in the main crack. If the contour of the cracks becomes particularly irregular, this approach can result in false secondary cracks. However, these cracks can later be excluded based on an analysis of crack length.

\section{Appendix B. Supplementary data}

Supplementary data associated with this article can be found in the online version.

\section{References}

[1] K. Wang, D. C. Jansen, S. P. Shah, A. F. Karr, Permeability study of cracked concrete, Cement and Concrete Research 27 (3) (1997) 381-393. doi:10.1016/S0008-8846(97)00031-8

[2] C. M. Aldea, S. Shah, A. Karr, Permeability of cracked concrete, Materials and Structures 32 (June) (1999) 370-376. 
[3] B. Pease, Influence of concrete cracking on ingress and reinforcement corrosion, Ph.D. thesis, Technical University of Denmark (2010).

[4] Beeby, Cracking, Cover and Corrosion of Reinforcement, Concrete International 5 (02) (1983) 35-40.

[5] T. U. Mohammed, N. Otsuki, M. Hisada, T. Shibata, Effect of Crack Width and Bar Types on Corrosionof Steel in Concrete, Journal of Materials in Civil Engineering 13 (3) (2001) 194-201. doi:10.1061/(ASCE) 0899-1561(2001)13:3(194)

[6] T. E. Maaddawy, K. Soudki, T. Topper, Long-term performance of corrosion-damaged reinforced concrete beams, ACI Structural Journal 102 (5) (2005) 649-656.

[7] M. Otieno, M. Alexander, H.-D. Beushausen, Corrosion in cracked and uncracked concrete - influence of crack width, concrete quality and crack reopening, Magazine of Concrete Research 62 (6) (2010) 393-404. doi:10.1680/macr.2010.62.6. 393

[8] R. François, G. Arliguie, Influence of Service Cracking on Reinforcement Steel Corrosion, Journal of Materials in Civil Engineering 10 (1) (1998) 14-20. doi:10.1061/(ASCE) 0899-1561(1998)10:1(14)

[9] A. Castel, T. Vidal, R. François, G. Arliguie, Influence of steelconcrete interface quality on reinforcement corrosion induced by chlorides, Magazine of Concrete Research 55 (2) (2003) 151-159. doi:10.1680/macr.55.2.151.37568

[10] B. Pease, M. Geiker, H. Stang, J. Weiss, The design of an instrumented rebar for assessment of corrosion in cracked reinforced concrete, Materials and Structures 44 (7) (2010) 12591271. doi:10.1617/s11527-010-9698-1

[11] N. Silva, Chloride Induced Corrosion of Reinforcement Steel in Concrete. Threshold Values and Ion Distributions at the Concrete-Steel Interface, Ph.D. thesis, Chalmers University of Technology, Gothenburg, Sweden (2013).

[12] A. Michel, A. Solgaard, B. Pease, M. Geiker, H. Stang, J. Olesen, Experimental investigation of the relation between damage at the concrete-steel interface and initiation of reinforcement corrosion in plain and fibre reinforced concrete, Corrosion Science 77 (2013) 308-321. doi:10.1016/j.corsci.2013.08.019.

[13] J. P. Romualdi, J. A. Mandel, Tensile Strength of concrete Affected by Uniformly Distributed and Closely Spaced Short Lengths of wire Reinforcement, ACI Journal Proceedings 61 (6) (1964) 657-672. doi:10.14359/7801.

[14] I. Löfgren, Fibre-reinforced concrete for industrial construction - a fracture mechanics approach to material testing and structural analysis, Ph.D. thesis, Chalmers University of Technology (2005).

[15] A. Bentur, S. Mindess, Fibre reinforced cementitious composites, 2nd Edition, Taylor \& Francis, Abingdon, United Kingdom, 2007.

[16] A. Jansson, M. Flansbjer, I. Löfgren, K. Lundgren, K. Gylltoft, Experimental investigation of surface crack initiation, propagation and tension stiffening in self-compacting steel-fibrereinforced concrete, Materials and Structures 45 (8) (2012) 1127-1143. doi:10.1617/s11527-012-9821-6

[17] B. B. Broms, Crack Width and Crack Spacing in Reinforced Concrete Members, ACI Journal Proceedings 62 (10) (1965) 1237-1256.

[18] Y. Goto, Cracks Formed in Concrete Around Deformed Tension Bars, ACI Journal Proceedings 68 (4) (1971) 244-251. doi: 10.14359/11325

[19] S. Husain, P. M. Ferguson, Flexural Crack Width at the Bars in Reinforced Concrete Beams, Tech. Rep. June, Center for Highway Research, The University of Texas, Austin, Texas (1968).

[20] A. Borosnyói, I. Snóbli, Crack width variation within the concrete cover of reinforced concrete members, ÉpítÅŚanyag 62 (3) (2010) 70-74.

[21] K. Otsuka, H. Mihashi, M. Kiyota, S. Mori, A. Kawamata, Observation of Multiple Cracking in Hybrid FRCC at Micro and Meso Levels, Journal of Advanced Concrete Technology 1 (3) (2003) 291-298. doi:10.3151/jact.1.291

[22] L. H. Lárusson, Development of Flexible Link Slabs using Duc- tile Fiber Reinforced Concrete, Ph.D. thesis, Technical University of Denmark (2013).

[23] A. Ammouche, J. Riss, D. Breysse, J. Marchand, Image analysis for the automated study of microcracks in concrete, Cement and Concrete Composites 23 (2-3) (2001) 267-278. doi:10.1016/ S0958-9465(00) 00054-8

[24] C. Qi, J. Weiss, J. Olek, Characterization of plastic shrinkage cracking in fiber reinforced concrete using image analysis and a modified Weibull function, Materials and Structures 36 (July) (2003) 386-395.

[25] J. Illston, R. Stevens, Long-Term Cracking in Reinforced Concrete Beams, Proceedings of the Institution of Civil Engineers 53 (1972) 445-459.

[26] H. Hornain, J. Marchand, A. Ammouche, J. Commène, M. Moranville, Microscopic Observation of Cracks in Concrete - A new sample preparation technique using dye impregnation, Cement and Concrete Research 26 (4) (1996) 573-583.

[27] N. Görander, C. Halldén, Crack Width Profiles for Fibre- reinforced Concrete Elements with Conventional Reinforcement, Tech. rep., Master thesis, Chalmers University of Technology, Göteborg, Sweden (2015).

[28] EN 14651:2007 Test method for metallic fibered concrete - Measuring the flexural tensile strength (limit of proportionality (LOP), residual) (2007).

[29] EN 12390-3:2009 Testing hardened concrete. Part 3: Compressive strength of test specimens (2009).

[30] EN 12390-6:2001 Testing hardened concrete. Tensile splitting strength of test specimens (2001).

[31] M. Abramoff, P. Magalhaes, S. Ram, Image Processing with ImageJ, Biophotonics International 11 (7) (2004) 36-42.

[32] B. Massey, Mechanics of Fluids, 3rd Edition, Van Nostrand Reinhold, London, UK, 1976.

[33] A. Akhavan, S.-M.-H. Shafaatian, F. Rajabipour, Quantifying the effects of crack width, tortuosity, and roughness on water permeability of cracked mortars, Cement and Concrete Research 42 (2) (2012) 313-320. doi:10.1016/j.cemconres.2011. 10.002

[34] Matlab, Matlab:2014 The MathWorks Inc., Natick, Massachusetts, 2014.

URL www . mathworks . com/products/matlab

[35] C. Edvardsen, Water Permeability and Autogenous Healing of Cracks in Concrete, ACI Materials Journal 96 (4) (1999) 448455.

[36] J. Rapoport, C.-M. Aldea, S. P. Shah, B. Ankenman, A. Karr, Permeability of Cracked Steel Fiber-Reinforced Concrete, Journal of Materials in Civil Engineering 14 (4) (2002) 355.

[37] J.-P. Charron, E. Denarié, E. Brühwiler, Permeability of ultra high performance fiber reinforced concretes (UHPFRC) under high stresses, Materials and Structures 40 (3) (2006) 269-277. doi:10.1617/s11527-006-9105-0.

[38] J. S. Lawler, D. Zampini, S. P. Shah, Permeability of Cracked Hybrid Fiber-Reinforced Mortar under Load, ACI materials Journal 99 (4) (2002) 379-385. 